\title{
PELATIHAN PENGENALAN TANAMAN HIDROPONIK KEPADA ANAK-ANAK DI RPTRA BAUNG JAKARTA SELATAN
}

\author{
Sidik Awaludin'), Wiji Pratomo ${ }^{2)}$, Azka Ramadhanty), Yayu Sriwartini ${ }^{4)}$ \\ Ilmu Komunikasi, FISIP, Universitas Nasional
}

\begin{abstract}
Abstrak
Tanaman Hidroponik adalah alternatif bercocok tanam yang memanfaatkan air tanpa menggunakan tanah dengan menekankan pada pemenuhan kebutuhan nutrisi bagi tanaman. Memperkenalkan tanaman hidroponik kepada anak-anak dapat dimulai dari lingkungan sosial yang paling sederhana, salah satunya di Ruang Publik Terpadu Ramah Anak (RPTRA). Tiga Mahasiswa Universitas Nasional melakukan kegiatan pengenalan dan pelatihan terhadap tanaman hidroponik kepada anak-anak di RPTRA Baung, di Jalan Baung III, Rt 04/Rw 02, Kebagusan, Jakarta Selatan. Kegiatan ini berlangsung satu hari, pada tanggal 22 Desember 2019, pukul 12:30 - 14:00 Wib. Dengan pemberian beberapa materi tentang tanaman hidroponik, mulai dari penyemaian bibit, hingga perakitan paralon untuk netpot hidroponik. Pemberian pelatihan tanaman hidroponik ini dapat memberi wawasan sekaligus pengetahuan bagimana sistem penanaman tanaman hidroponik. Selain untuk memperkenalkan tanaman hidroponik, tutorial kit ini juga bersifat interaktif sehingga informasi yang disampaikan dapat dipraktikan langsung oleh anak-anak. Hasil yang diperoleh dari pengenalan dan pelatihan ini adalah besarnya antusias anak-anak di RPTRA Baung untuk mau belajar bercocok tanam melalui sistem hidroponik, dan kemdian mereka bisa merakit sendiri paralon netpot tanaman hidroponik.
\end{abstract}

Kata Kunci : Hidroponik, Anak-anak, Tutorial Kit.

\begin{abstract}
Hydroponic plants are alternatives to farming that utilize water without using soil by emphasizing meeting the nutritional needs of plants. Introducing hydroponic plants to children can be started from the simplest social environment, one of which is in the Child Friendly Integrated Public Space (RPTRA). Three National University Students conducted an introduction and training program on hydroponic plants for children at RPTRA Baung, on Jalan Baung III, Rt 04 / Rw 02, Kebagusan, South Jakarta. This activity took place one day, on December 22, 2019, 12:30 - 14:00 WIB. By providing some material on hydroponic plants, starting from seeding seedlings, to assembling paralons for hydroponic netpots. The provision of hydroponic plant training can provide insight as well as knowledge of the hydroponic plant planting system. In addition to introducing hydroponic plants, this tutorial kit is also interactive so that the information conveyed can be practiced directly by children. The results obtained from the introduction and training were the great enthusiasm of children in the Baung RPTRA to want to learn to grow crops through the hydroponic system, and then they could assemble the netpot paralons of the hydroponic plants.

Keywords : Hydroponics, Children, Tutorial Kit.
\end{abstract}

Correspondence author: Sidik Awaludin, sidikfals68@gmail.com, Jakarta, Indonesia

This work is licensed under a $C C-B Y-N C$ 


\section{PENDAHULUAN}

Saat ini tengah tumbuh hunian dengan halaman yang terbatas, terlebih di daerah perkotaan seperti Jakarta yang disesaki Gedung perkantoran. Didasarkan pada hal tersebut, maka jarang dijumpai area ruang terbuka hijau sebagai media tanam sayur dan buah (Nugroho, 2016). Pola bangunan warga kota adalah apartemen dan perumahan minimalis dimana notabene warga memiliki luas tanah yang sempit, kondisi tanah yang kritis dan keterbatasan jumlah air. Maka hal tersebut dibutuhkan solusi agar warga kota dapat bercocok tanam. Didasarkan hal tersebut, pola tanam hidroponik menjadi salah satu alternatif yang baik bagi warga kota agar tetap dapat bercocok tanam dilingkungan sekitarnya.

Isu lain yang cukup signifikan adalah Pengetahuan anak-anak tentang tanaman hidroponik dapat dikatakan masih kurang. Informasi tentang tanaman hidroponik pun masih sangat sedikit. Perlu adanya pengenalan bercocok tanam secara hidroponik ini agar mereka dapat merasakan sendiri manfaatnya. Cara pengenalannya dapat melalui buku tutorial menaman tanaman hidroponik sederhana, tutorial kit, poster, brosur dan sebagainya, sehingga anak-anak mengetahui dasar dari sistem menanam secara hidroponik. Pengenalan dasar yang dapat disampaikan kepada anak-anak berupa informasi yang menjelaskan apa itu tanaman hidroponik dan bagaimana cara menamannya.

Isu lain yang cukup menjadi perhatian di kalangan masyarakat Jakarta adalah produksi makanan yang sehat. Saat ini, kesadaran masyarakat Jakarta untuk mengkonsumsi sayuran dan buah-buahan yang minim pestisida meningkat cukup signifikan. Oleh karea itu dibutuhkan sebuah alternatif solusi untuk dapat memenuhi kebutuhan sayuran dan buah-buahan yang minim pestisida.

Pola tanam hidroponik merupakan solusi baru bagi warga kota Jakarta untuk dapat bercocok tanam di lingkungan sekitar. Hidroponik awalnya dikenalkan oleh William Frederick Gericke dari Universitas California di Berkeley yang mulai mempromosikan secara terbuka tentang Solution culture yang digunakan untuk menghasilkan tanaman pertanian. Hingga kemudian pada tahun 1937 Gerick menciptakan istilah hidroponik untuk budidaya tanaman air.Hidroponik berasal dari bahasa Latin yang berarti hydro (air) dan ponos (kerja). Selanjutnya hidroponik didefinisikan secara ilmiah sebagai suatu cara budidaya tanaman tanpa menggunakan tanah, akan tetapi menggunakan media inert seperti gravel, pasir, peat, vermikulit, pumice atau sawdust, yang diberikan larutan hara yang mengandung semua elemen essensial yang diperlukan untuk pertumbuhan dan perkembangan normal tanaman (Resh, 1998).

Hidroponik merupakan metode yang sangat cocok digunakan, karena hal tersebut dapat untuk mengurangi (1) kebutuhan air, (2) risiko makanan yang tidak sehat, (3) pencemaran lingkungan. Berkebun bagi sebagian orang apalagi yang berasal dari kota tidak hanya sekedar sebagai hobi saja melainkan juga salah satu bentuk tindakan untuk mendukung ketahanan pangan, memperindah lingkungan dan bagi yang menekuninya dengan serius akan mampu meraup keuntungan dalam jumlah besar (Harris, 1988).

Hidroponik menjadi salah satu metode bercocok tanam yang biasanya digunakan untuk menanam sayuran. Sayuran merupakan sumber vitamin dan mineral yang sangat dibutuhkan tubuh. Sebagai upaya untuk memenuhi sumber vitamin dan mineral maka warga kota dapat memanfaatkan pekarangannya yang sempit. Contoh sayuran yang biasanya ditanam dengan menggunakan hidroponik adalah sawi, bayam, selada, kangkung, tomat dan lain-lain. 
Seiring dengan bertambahnya jumlah penduduk di Jakarta, ada fakta yang bisa kita temui saat ini salah satunya adalah semakin berkurangnya lahan hijau atau lahan untuk bercocok tanam. Namun demikian lahan hijau atau lahan bercocok tanam di Jakarta tetap diperlukan. Untuk itu salah satu alternatif mewujudkan lahan bercocok tanam di ruang yang terbatas adalah dengan tanaman hidroponik. Oleh sebab itu, pengenalan terhadap tanaman hidroponik harus dilakukan kepada anak-anak dengan maksud agar anak-anak bisa memahami sejak dini mengenai bagaimana bercocok tanam dengan lahan yang sempit atau terbatas namun tetap bisa menghasilkan dari segi nilai ekonomis.

Pengenalan tanaman hidroponik di lingkungan RPTRA dimaksudkan bahwa RPTRA selain merupakan sarana anak-anak untuk bermain, juga diharapkan bisa menjadi tempat yang tepat untuk memberikan ilmu pengenalan cara bercocok tanam dengan metode hidroponik. RPTRA Baung ini dipilih, karena di wilayah Kebagusan, Jakarta Selatan ini merupakan salah satu wilayah yang tergolong pemukiman padat penduduk, bukan hanya pemukiman perumahan biasa, tetapi di wilayah Kebagusan ini juga sudah banyak bermunculan apartemen-apartemen dan cluster-cluster perumahan, sehingga sangat sulit untuk menemukan lahan hijau atau lahan bercocok tanam.

Program-program yang dimiliki baik oleh pengurus Ruang Publik Terpadu Ramah Anak (RPTRA) Baung maupun Karang Taruna masyarakat setempat, tidak semuanya berjalan sesuai harapan. Ada beberapa permasalahan yang cukup menonjol, yakni:

1. Selama ini di Ruang Publik Terpadu Ramah Anak (RPTRA) masih mengandalkan bantuan para donatur dalam hal ini seperti pengisian program kegiatan-kegiatan yang terselenggara dari program csr perusahaan maupun akademisi seperti perguruan tinggi. Dari pemprov DKI Jakarta sendiri hanya memberikan anggaran untuk biaya pengurusan bangunan dan fasilitas tempat bermain anak-anak saja.

2. Meskipun ada beberapa program kegiatan bulanan yang dilakukan oleh pengelola dari RPTRA Baung sendiri, kegiatan tersebut hanya sekedar "have fun" saja tanpa ada nilai-nilai edukasi yang bisa dipetik dari kegiatan tersebut. Hal semacam ini jelas merugikan mereka karena anak seumuran mereka seharusnya bisa memperoleh ilmu tidak hanya di dalam bangku sekolah tetapi bisa melalui sarana tempat mereka bermain bersama teman-teman sebayanya.

Tujuan dari kegiatan ini adalah memberikan pengenalan terhadap anak-anak dengan teknik bercocok tanam modern dengan ruang yang terbatas, sekaligus mengajarkan praktek pelatihan bagaimana anak-anak di RPTRA Baung tersebut bukan cuma memahami saja dari segi teori yang kita berikan tetapi bisa terampil mulai dari penyemaian bibit, merakitnya, sampai dengan teknik perawatannya.

\section{METODE PELAKSANAAN}

Pemberian materi tentang pengertian umum, cara, proses, tujuan, bahan media tanam, manfaat, dan alat pendukung kegiatan lainnya. Pembuatan tanaman hidroponik dengan memadukan konsep tutorial dan pengerjaan bersama-sama dengan maksud menumbuhkan keterampilan serta kreativitas.

Praktik bercocok tanam dengan media hidroponik diberikan kepada masing-masing anak-anak yang berjumlah 20 anak RPTRA Baung. Dalam pelaksanaannya mereka dibagi ke dalam 2 kelompok, sehingga masing-masing kelompok terdiri dari 10 anak yang didampingi oleh para instruktur. Dalam praktiknya anak-anak diberikan pemahaman mulai dari jenis bibit sayuran, teknik penyemaian bibit di dalam media rockwool dengan cara membasahi terlebih dahulu kemudian rockwool dilubangi menggunakan tusuk gigi, dilanjutkan dengan memasukkan bibit sayuran ke dalam rockwool yang sudah dilubangi. 
Kegiatan selanjutnya dilakukan dengan perakitan pipa paralon hidroponik, dimana anak-anak diajak untuk membantu melakukan perakitan, mulai dari pengelompokkan pipa sesuai ukuran hingga pemasangan dan peletakkan pot hidroponik. Pada sesi ini juga dikenalkan berbagai perlengkapan yang dibutuhkan seperti gambar berikut ini.

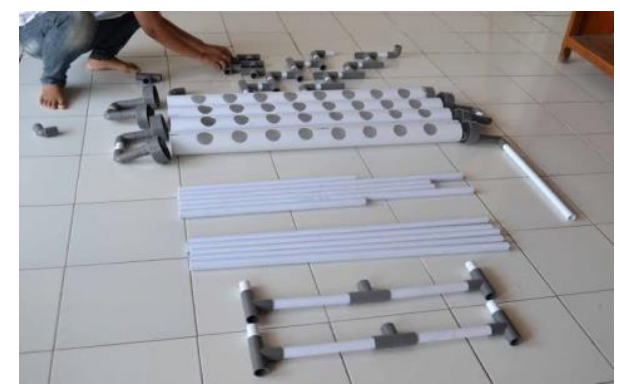

Gambar 1. Pipa Pralon

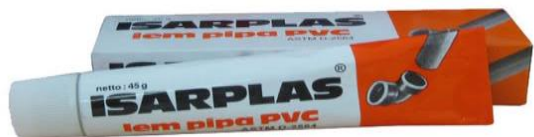

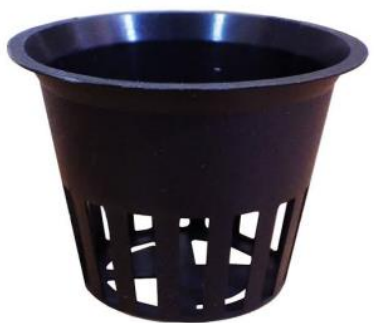

Gambar 3. Pot Hidroponik

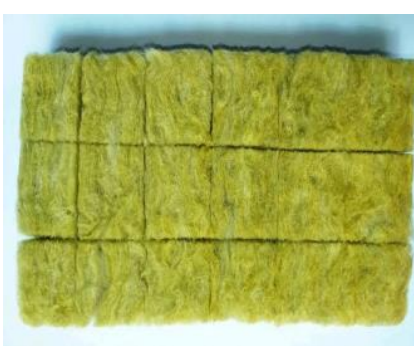

Gambar 4. Rockwool
Gambar 2. Lem Pralon

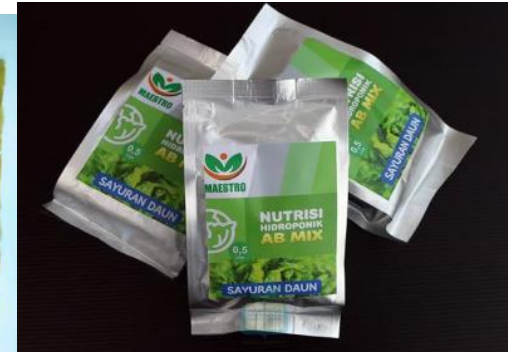

Gambar 5. Benih Kangkung

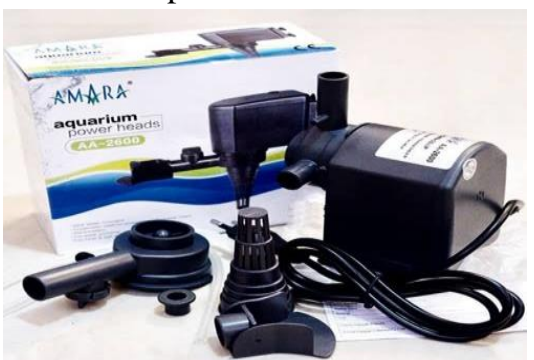

Gambar 6. Pompa Air

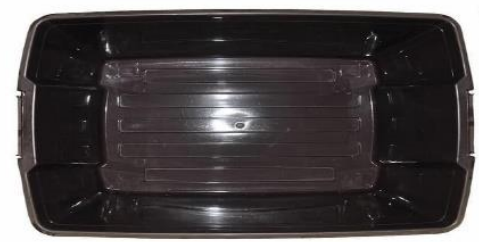

Gambar 7. Bak Penampung Air

\section{Waktu dan Tempat Pelaksanaan}

Kegiatan pengabdian masyarakat ini diawali dengan mengurus perizinan lokasi RPTRA yang sebelumnya sudah dipilih, sampai dengan meninjau langsung lokasi yang dilaksanakan pada 15 Desember 2019. Dalam pelaksanaan kegiatan pengabdian masyarakat ini dimulai pada tanggal 22 Desember 2019 pukul 12:30 - 14:30 WIB.

\section{Tempat Pelaksanaan}

Tempat kegiatan pengabdian masyarakat ini dilaksanakan di Ruang Publik Terpadu Ramah Anak (RPTRA) Baung, yang beralamat di Jln. Baung 3, Rt. 04/Rw. 02, Kebagusan, Kec. Ps. Minggu, Kota Jakarta Selatan, Daerah Khusus Ibukota Jakarta 12520.

\section{HASIL DAN PEMBAHASAN}

Hasil evaluasi setelah selesainya dari kegiatan pelatihan dan pengenalan tanaman hidroponik kepada anak-anak di RPTRA Baung Jakarta Selatan sangatlah antusias. Hal 
ini nampak dari kecepatan dan ketepatan anak-anak tersebut dalam merangkai struktur paralon netpot hidroponik.

Hal ini dibuktikan dengan banyaknya anak-anak yang tertarik untuk berpartisipasi merakit pipa paralon tanaman hidroponik, selain itu juga anak-anak sangat bersemangat sekali untuk mengetahui bagaimana cara menyemai bibit dan bahkan ketika mereka memasang sambungan-sambungan pipa pralon hidroponik sampai berebutan. Selain itu, dengan bekal pelatihan pengenalan tentang cara bercocok tanam menggunakan media hidroponik yang diberikan kepada anak-anak di RPTRA Baung ini dapat memberikan manfaat bagi anak-anak dan juga warga sekitar RPTRA Baung, mengingat tanaman hidroponik saat ini sudah mulai ramai atau banyak orang yang menggunakannya.

Adapun salah satu hasil luaran dari pelatihan dan pengenalan ini adalah untuk menanamkan pengetahuan bercocok tanam para anak-anak sejak dini dengan menggunakan teknik hidroponik yang baik di lahan yang terbatas. Khususnya di wilayah seputar RPTRA Baung Kebagusan, sehingga nantinya hidroponik ini bisa dimanfaatkan menjadi konsumsi sayuran sehat yang kaya akan vitamin untuk perkembangan anak.

Pelatihan yang dilaksanakan pada hari Minggu, 22 Desember Pukul 12:30 - 14:30 Wib dengan jumlah peserta yang berpartisipasi berjumlah 20 anak dengan rentang usia 10 tahun sampai 15 tahun. Rata-rata seluruh peserta merupakan siswa sekolah SD-SMP. Media pertama yang digunakan untuk pembelajaran adalah Rockwool, dalam pertanian, Rockwool berfungsi sebagai media untuk penyemaian bibit sayuran hidroponik dengan kelebihan bersifat permanen, dapat dipakai dalam jangka waktu yang lama, dan sterilitasnya lebih terjamin sehingga aman dari hama perusak tanaman. Berikut ini adalah hasilnya:
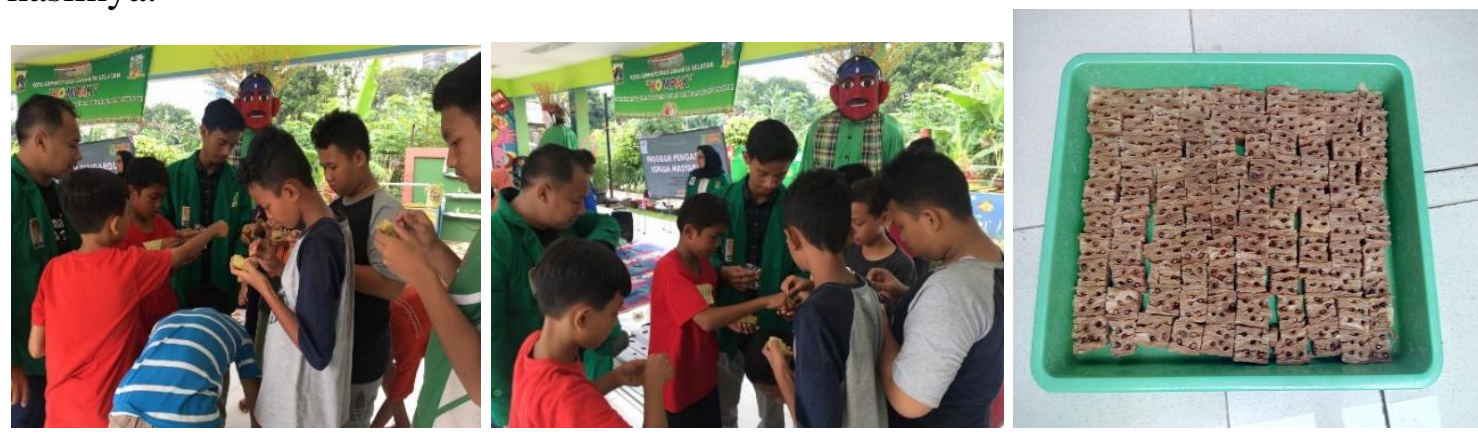

Gambar 8, 9 dan 10. Menyemai bibit sayuran kangkung pada media Rockwool

Setelah semua rangkaian proses penyemaian bibit sayuran kangkung menggunakan media rockwool selesai, dilanjutkan pada tahap berikutnya yaitu dengan merangkai pipapipa pralon disusun sehingga dapat terbentuk sesuai yang di inginkan. Berikut adalah hasilnya:
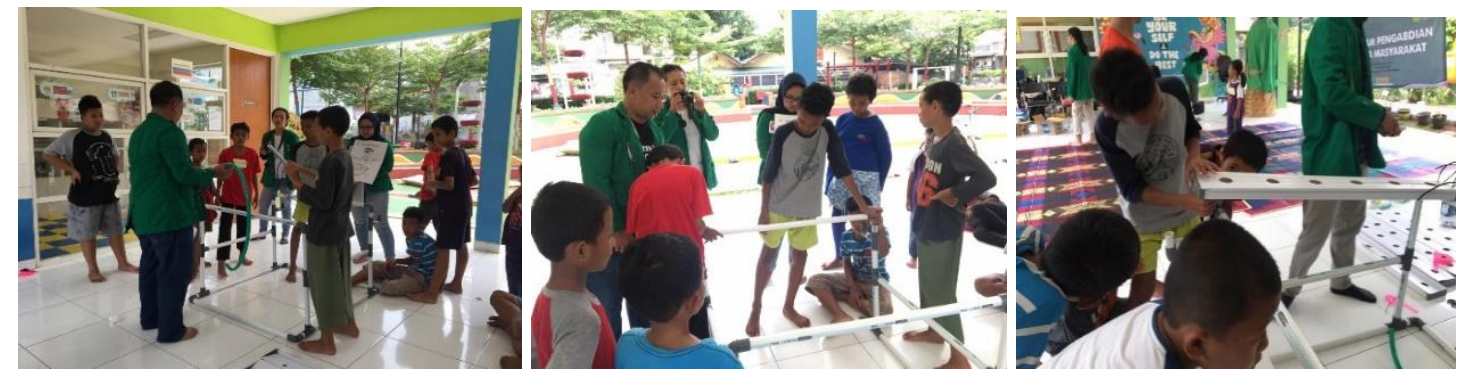

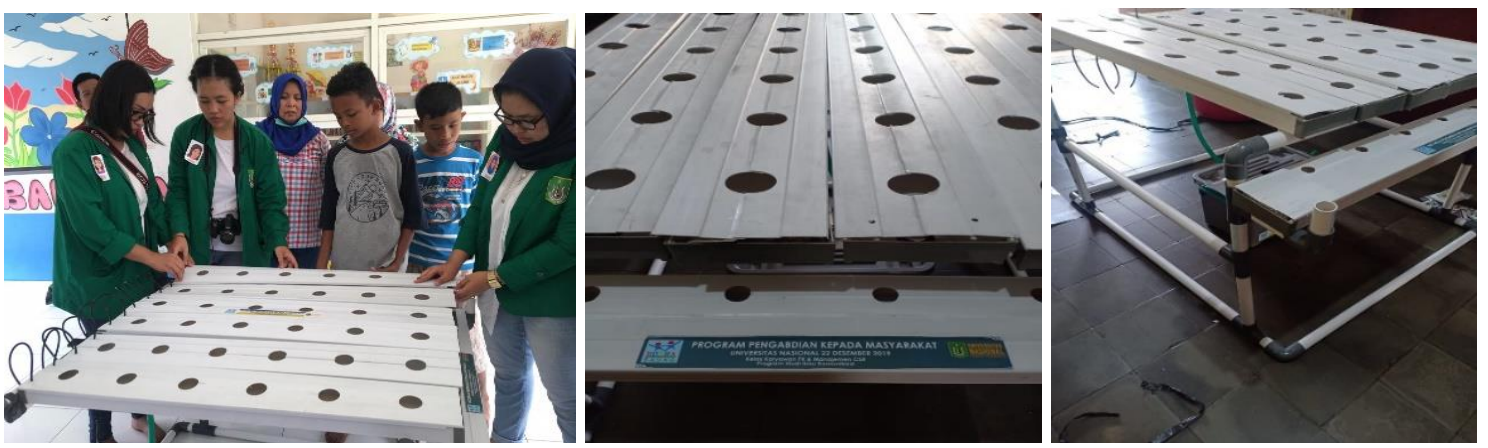

Gambar 11,12, 13, 14,15 dan 16. Proses perakitan pipa pralon hidroponik

Pada tahap awal, anak-anak diberikan pengenalan terhadap alat-alat dan kelengkapan tanaman hidroponik. Pada tahapan ini respon anak-anak sangat antusias. Hal ini tergambar dari pahamnya anak-anak tersebut, dalam menjawab pertanyaan seputar alat-alat kelengkapan tanaman hidroponik seperti paralon, bibit dan media tanam. Tahap selanjutnya yaitu pemberian materi dan praktek penyemaian bibit tanaman sayuran (kangkung) dengan menggunakan media tanam rockwool. Pada tahapan ini anak-anak mampu mempraktikan penyemaian bibit tanaman ke dalam rockwool. Tahap selanjutnya adalah pelatihan perakitan paralon dan pot tanaman hidroponik. Pada tahap ini anak-anak mampu melakukan perakitan sendiri, paralon dan pot tanaman hidroponik.

Adapun hasil luaran lain dalam kegiatan ini adalah membuat laporan penulisan yang dimuat di media massa online www.jpnn.com.

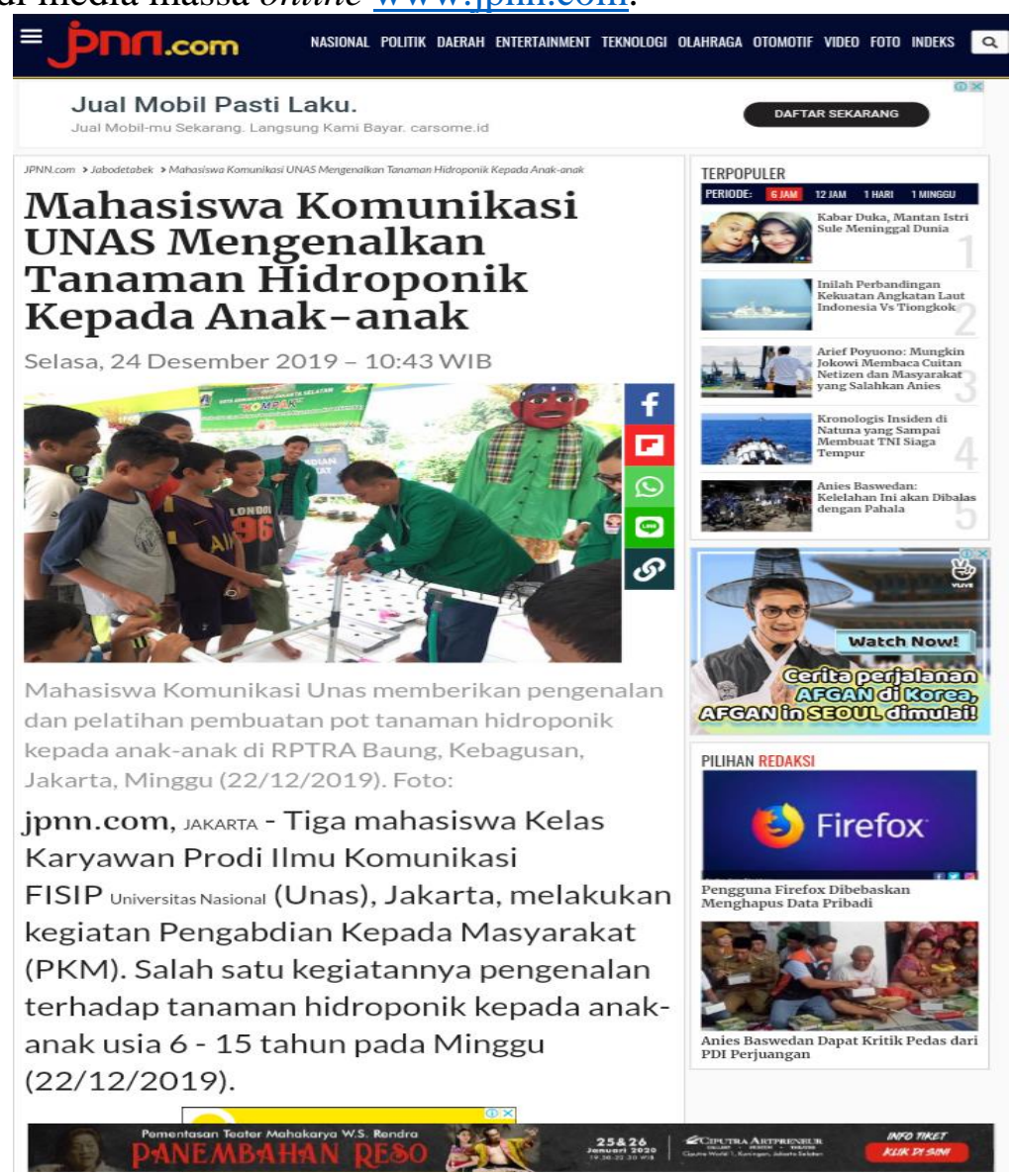

Gambar 17. Berita online kegiatan pelatihan pengenalan tanaman hidroponik 


\section{SIMPULAN}

Memberikan pelatihan pengenalan bercocok tanam menggunakan media hidroponik kepada anak-anak dengan maksud agar anak-anak bisa memahami sejak dini mengenai bagaimana bercocok tanam dengan lahan yang sempit atau terbatas namun tetap bisa menghasilkan dari segi nilai ekonomis. Dengan belajar mengenal media bercocok tanam hidroponik anak-anak dilatih untuk memiliki kreativitas, teliti, dan tidak pantang menyerah. Jika anak-anak sudah piawai membuat dan mempraktekannya sendiri prakarya ini, mereka dapat menyebarluaskan di lingkungan tempat tinggalnya dengan harapan bisa menjadikan bekal softskill anak-anak kelak di masa depan.

\section{DAFTAR PUSTAKA}

Budianti, Indah. (2014). Implikasi Minat Siswa Dalam Pengelolaan Pertanian Terhadap Keberlanjutan Minat Bertani di Wilayah Kecamatan Parongpong. Jurnal Pendidikan Ilmu Sosial. 23.(2):103.

Hendra, Heru Agus dan Andoko, Agus. (2014). Bertanam Sayuran Hidroponik Ala Paktani Hydrofarm. Jakarta: Agromedia Pustaka.

Siswadi. (2015). Pengaruh Macam Media Terhadap Pertumbuhan dan Hasil Selada (Lactuca Sativa L) Hidroponik. Jurnal Agronomika. 09.(03):260.

Suryani, Reno. (2015). Hidroponik Budidaya Tanaman Tanpa Tanah. Yogyakarta: PT. Pustaka Baru.

http://hidroponiq.com/2014/07/sistem-nft-nutrient-film-technique, diakses pada tanggal 26 Desember 2019 pukul 21:00 WIB.

http://mandonhidroponik.blogspot.co.id/2015/12/hidroponik.html, diakses pada tanggal 26 Desember 2019 pukul 21:15 WIB.

http://www.sistemhidroponik.com/hidroponik-dengan-zeolit-serta-kelebihannya, diakses pada tanggal 26 Desember 2019 pukul 21:25 WIB.

http://www.kebunpedia.com, diakses pada tanggal 26 Desember 2019 pukul 21:35 WIB. http://www.batatahanapi.net/rockwool-murah.html, diakses pada tanggal 26 Desember 2019 pukul 21:40 WIB. 